\title{
Apoptotic effects of proteasome and histone deacetylase inhibitors in prostate cancer cell lines
}

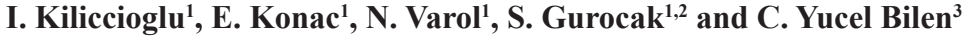 \\ ${ }^{1}$ Department of Medical Biology and Genetics, Faculty of Medicine, \\ Gazi University, Besevler, Ankara, Turkey \\ ${ }^{2}$ Department of Urology, Faculty of Medicine, Gazi University, \\ Besevler, Ankara, Turkey \\ ${ }^{3}$ Department of Urology, Faculty of Medicine, Hacettepe University, \\ Sihhiye, Ankara, Turkey \\ Corresponding author: E. Konac \\ E-mail: ecemercanoglu@yahoo.com
}

Genet. Mol. Res. 13 (2): 3721-3731 (2014)

Received November 22, 2013

Accepted February 14, 2014

Published May 9, 2014

DOI http://dx.doi.org/10.4238/2014.May.9.17

\begin{abstract}
Prostate cancer is one of the most common types of urological cancers. Despite the implementation of effective radiotherapy and chemotherapy methods, prostate cancer cells can still show resistance to treatment. In recent years, a combination of proteasome and histone deacetylase inhibitors has been used to treat various malignancies. In this study, we examined the cytotoxic and apoptotic effects of the proteasome inhibitor bortezomib (Velcade/PS-341) and histone deacetylase inhibitor trichostatin A (TSA), used either alone or in combination, on the human prostate LNCaP and PC3 cell lines. We investigated the cytotoxic activity of these inhibitors using a WST1 assay, IkB $\alpha$ and caspase- 3 mRNA levels by real-time polymerase chain reaction, and caspase- 3 activity and activation of phosphorylated $(\mathrm{p}-\mathrm{IkB} \alpha)$ protein by Western blotting. Low-dose bortezomib and TSA synergistically induced apoptosis in both prostate cancer cell
\end{abstract}


lines. Combination treatment with TSA with bortezomib effectively inactivated NFkB signaling, upregulated the predominant endogenous apoptotic factor caspase-3, and disrupted the NFkB pathway in the androgen-independent PC3 cell line. In contrast, androgen-dependent LNCaP cells showed upregulation of caspase- 3 through a pathway other than NFkB. This study examined the possible clinical use of bortezomib and TSA, together with reduced doses of chemotherapeutic agents with high cytotoxicity, to determine their apoptotic effects on the NFkB pathway in prostate cancer cell lines. Therefore, combination bortezomib and TSA treatment may represent a novel therapeutic strategy for prostate cancer.

Key words: Apoptosis; Bortezomib; NFkB pathway; Prostate cancer; Trichostatin A

\section{INTRODUCTION}

Prostate cancer is one of the most common cancers in males and ranks 2nd among cancer-related deaths in most western countries. It is also one of the most common urological malignancies. Despite the development of effective radiotherapy and chemotherapy methods, prostate cancer cells occasionally show resistance to treatment. Thus, the apoptotic potential of prostate cancer cells is expected to increase with the variety of agents that are being tested (Ramsay and Leung, 2009; Verma et al., 2011).

The ubiquitin proteasome pathway is the major pathway for intracellular protein degradation. This pathway is involved in the cell cycle, apoptosis, transcription, DNA repair, protein quality control, and antigen presentation (Crawford et al., 2011). The $26 \mathrm{~S}$ proteasome complex regulates degradation of intracellular proteins involved in key regulatory cellular processes. This complex plays an important role in maintaining normal cellular functions. Altered regulation of cellular events is linked to the development of various diseases, including cancer. Therefore, the proteasome has become an attractive target for the treatment of numerous cancers (Frankland-Searby and Bhaumik, 2012). Inhibition of the ubiquitin proteasome pathway by proteasome inhibitors is a potential therapeutic approach for cancer and inflammatory diseases (Chitra et al., 2012). Bortezomib (also known as Velcade and PS-341) is a dipeptidyl boronic acid that reversibly inhibits the chemotrypsin-like activity of the proteasome. Clinical activity of bortezomib was demonstrated in the treatment of patients with multiple myeloma and non-Hodgkin lymphoma (Yeramian et al., 2012). Experimental studies showed that bortezomib potently induces apoptosis in a wide range of human cancer cell lines, including myeloma, melanoma, breast, head and neck squamous carcinoma, pancreas, and prostate (Bai et al., 2006; Kim et. al., 2010; Shahshahan et al., 2011; Voutsadakis and Papandreou, 2012). In preclinical experiments, bortezomib induced growth arrest and apoptosis in many tumor types, including androgen-dependent $(\mathrm{LNCaP})$ and androgen-independent prostate cancer cell lines (PC3 and DU145). These experiments indicated that proteasome inhibition may be a novel method for treating androgen-dependent and androgen-independent prostate cancer (Papandreou and Logothetis, 2004).

Activation of nuclear factor kappa B (NFkB) is key for the survival of cancer cells. It has been shown that this pathway depends on the $26 \mathrm{~S}$ proteasome. Inhibition of the $26 \mathrm{~S}$ 
proteasome by bortezomib results in inhibition of the NFkB pathway (Fribley et al., 2004). Constitutive activation of transcription factor NFkB may also be associated with more aggressive prostate cancers. Inhibition of the $26 \mathrm{~S}$ proteasome by bortezomib prevents degradation of the inhibitor of $\mathrm{NFkB}(\mathrm{IkB} \alpha)$ and results in cytoplasmic NFkB inhibition by binding to $\mathrm{IkB} \alpha$. In this way, NFkB cannot translocate to the nucleus, where it typically binds to the promoters of its target genes, including interleukin-6, vascular cell adhesion molecule, E-selectin, cyclooxygenase-2, inhibitors of apoptosis proteins, and the anti-apoptotic $\mathrm{Bcl} 2$ family. These genes are important for tumor growth, angiogenesis, metastasis, and resistance to chemotherapy in both solid and hematological malignancies. Therefore, NFkB pathway inhibition is a potential target for cancer treatment (Papandreou and Logothetis, 2004).

A number of investigators have examined the combined use of proteasome and histone deacetylase inhibitors, which showed a synergistic effect in some malignant tumors such as human multiple myeloma, non-small cell lung cancer, head and neck squamous carcinoma, pancreatic cancer, ovarian cancer, and prostate cancer (Bai et al., 2006; Kim et al., 2010; Fang et al., 2011; Sato et al., 2012). Previous reports have shown that co-administration of these reagents may increase caspase activation and apoptosis (Fang et al., 2011).

The acetylation status of histone proteins, which is an important epigenetic regulation, is mediated by histone acetyltransferases and deacetylases (HDACs). Although this process is typically well-regulated, this regulation is often upset in various cancer types (Kim and Bae, 2011; Sato et al., 2012). Thus, HDACs are important targets for therapeutic intervention in both hematological and solid malignancies (Ellis and Pili, 2010). HDAC inhibitors, which are emerging as a new class of anti-cancer agents, were shown to have anti-proliferation, pro-differentiating, and pro-apoptotic properties in cancer cells, including prostate cancer cells (Zhu et al., 2012). Among the well-established HDAC inhibitors, trichostatin A (TSA) represents the hydroxamic acids, which show general inhibition of class 1, 2, and 4 HDACs with nanomolar potency (Chang et al., 2012). TSA was studied in vivo and in vitro in various cancers and was shown to have antitumor activities (Mukhopadhyay et al., 2006; Fang et al., 2011; Tavakoli-Yaraki et al., 2013). In a study of prostate cancer cell lines, TSA was found to induce apoptosis via caspase activation (Taghiyev et al., 2006).

In this study, we hypothesized that combination treatment with low-dose bortezomib and TSA would maximize the killing of prostate cancer cells from diverse sources. We investigated the cytotoxic effects of bortezomib and TSA in 2 different prostate cancer cell lines, LN$\mathrm{CaP}$ and $\mathrm{PC} 3$. Additionally, we investigated the synergistic effects of the drugs on inhibition of the NFkB signaling pathway and caspase activation process of these cells by determining mRNA and protein expression levels. Inhibition of the NFkB signaling pathway by the proteasome and HDAC inhibitors may offer a novel strategy for prostate cancer treatment.

\section{MATERIAL AND METHODS}

\section{Cell culture and reagents}

The prostate cancer cell lines LNCaP and PC3 were provided by Prof. Levent Türkeri (Department of Urology, Faculty of Medicine, Marmara University, Istanbul, Turkey). These cell lines were cultured in RPMI medium containing $10 \%$ fetal bovine serum and $1 \%$ penicillin-streptomycin. Cells were maintained at $37^{\circ} \mathrm{C}$ with $5 \%$ carbon dioxide. Bortezomib was purchased from BioVision and dissolved in dimethylsulfoxide at a concentration of $1 \mathrm{mM}$ 
and stored at $-20^{\circ} \mathrm{C}$. Stock solutions were diluted to their working concentrations with growth medium just before use. TSA was purchased from Cell Signaling Technology Inc. (Danvers, MA, USA) and was dissolved in ethanol as a $1 \mathrm{mM}$ stock solution and stored at $-20^{\circ} \mathrm{C}$. TSA was diluted with cell culture medium before use.

\section{Cell viability assay}

Cells $\left(5 \times 10^{3}\right.$ per well) were plated on 96-well culture plates for before exposure to different concentrations of bortezomib alone and in combination with TSA. The cells were treated with $5,10,15,20,40$, and $50 \mathrm{nM}$ bortezomib alone for $24-48 \mathrm{~h}$ and bortezomib plus 200 and $300 \mathrm{nM}$ TSA for $24 \mathrm{~h}$. Cell proliferation and viability were assayed using the WST-1 assay (Roche Diagnostics, Basel, Switzerland). To each well, $10 \mu \mathrm{L}$ WST-1 were added and the cells were incubated for $4 \mathrm{~h}$ at $37^{\circ} \mathrm{C}$. After incubation, the absorbance of each well was measured spectrophotometrically at $450 \mathrm{~nm}$ using an enzyme-linked immunosorbent assay reader.

\section{Total RNA extraction and real-time polymerase chain reaction (PCR)}

Total RNA were prepared at the indicated time points from control and drug-treated LNCaP and PC3 prostate cancer cells using Tripure Isolation Reagent (Roche Diagnostics) following manufacturer instructions. RNA concentration was determined using a Nanodrop spectrophotometer (NanoDrop ND-1000; NanoDrop Technologies, Wilmington, DE, USA). cDNA was synthesized from $2 \mu \mathrm{g}$ total RNA using random hexamer primers with the Transcriptor First Strand cDNA Synthesis Kit (Roche Diagnostics) according to manufacturer instructions. IkB $\alpha$ and caspase-3 mRNA expression levels were measured using a Real TimePCR with a LightCycler480 instrument (Roche Diagnostics). Glyceraldehyde 3-phosphate dehydrogenase was used as the housekeeping gene in order to normalize expression levels. The gene-specific primer sequences and probe numbers are shown in Table 1 . The $20-\mu \mathrm{L}$ reaction mixture contained 1X LightCycler TaqMan Master reaction mixture (Roche Diagnostics), 2.5 pmol of each primer, 1 pmol Universal Probe Library, $4 \mathrm{mM} \mathrm{MgCl}$, and $1 \mu \mathrm{L} \mathrm{cDNA}$. Each sample was tested in triplicate. To determine the amplification efficiencies for each gene, standard curves were constructed from samples used in a series of dilutions for the 2 genes of interest and the housekeeping gene glyceraldehyde 3-phosphate dehydrogenase. The 2 genes of interest and glyceraldehyde 3-phosphate dehydrogenase amplification efficiencies were approximately equal.

\begin{tabular}{|c|c|c|c|}
\hline Gene & Forward primer & Reverse primer & UPL probe No. \\
\hline GAPDH & 5'-AGCCACATCGCTCAGACAC-3' & 5'-GCCCAATACGACCAAATCC-3' & 60 \\
\hline $\mathrm{IkB} \alpha$ & 5'-ATGGCCAAGTGCAGGAAC-3' & 5'-GTCAAGGAGCTGCAGGAGAT-3' & 38 \\
\hline Caspase-3 & 5'-CCACTGAGTTTTCAGTGTTCTCC-3' & 5'-CTGGTTTTCGGTGGGTGT-3' & 34 \\
\hline
\end{tabular}

\section{Protein isolation and Western blot analysis}

Cells $\left(2 \times 10^{6}\right)$ were plated on $10-\mathrm{cm}^{2}$ tissue culture dishes one day before bortezomib and/or TSA treatment. Whole cell lysate was obtained using RIPA buffer. Next, $35 \mu \mathrm{g}$ total 
protein lysate from each sample was loaded onto $8-12 \%$ sodium dodecyl sulfate-polyacrylamide gel electrophoresis gel and transferred onto a polyvinylidene fluoride membrane using a Bio-Rad wet-blot transfer apparatus (Bio-Rad, Hercules, CA, USA). The membrane was blotted with 5\% non-fat milk powder at room temperature for $1 \mathrm{~h}$. The membrane was probed with primary antibodies at $4^{\circ} \mathrm{C}$ overnight. The primary antibodies $\operatorname{IkB} \alpha, \mathrm{p}$-IkB $\alpha$ (mouse Ser32/36), caspase-3, and $\beta$-actin were purchased from Cell Signaling Technology. They were then incubated with the secondary antibody anti-rabbit IgG-HRP (Cell Signaling Technology) for $1 \mathrm{~h}$ to detect the primary antibodies. The signals were visualized using chemiluminescence solutions (Thermo Scientific, Waltham, MA, USA).

\section{Statistical analysis}

Comparisons between control and drug-treated cell group viability were analyzed using the SPSS software, version 15.0 (SPSS, Inc., Chicago, IL, USA). Gene expression analysis of $\mathrm{IkB} \alpha$ and caspase-3 were performed using the Relative Expression Software Tool 2009 version (REST) (Pfaffl et al., 2002). The results are reported as means \pm standard deviation of at least 3 independent experiments. Differences were considered to be significant in all experiments when $\mathrm{P}<0.05$.

\section{RESULTS}

\section{TSA and bortezomib effectively inhibits cell growth of prostate cancer cells}

To determine the effect of individual and combined exposure to bortezomib and TSA, LNCaP and PC3 cells were treated with bortezomib (5-50 nM) alone and TSA (100-1000 nM) alone for 24 and $48 \mathrm{~h}$ as well as with a combination of these drugs for $24 \mathrm{~h}$. TSA alone treatment was found to be less effective for inhibiting cell death compared to bortezomib alone treatment or combination treatment (data not shown). The viability of PC3 cells was found to be 49 and $12 \%$, whereas the viability of LNCaP cells was found to be 56 and $38 \%$ after treatment with the highest concentration of bortezomib $(50 \mathrm{nM})$ for 24 and $48 \mathrm{~h}$, respectively (Figure 1A and B). This inhibition effect was markedly enhanced with TSA plus low-dose bortezomib treatment for $24 \mathrm{~h}$. In PC3 and LNCaP cells, treatment with a combination of 20 $\mathrm{nM}$ bortezomib and $300 \mathrm{nM}$ TSA for $24 \mathrm{~h}$ resulted in 7 and $48 \%$ cell viability rates, respectively (Figure 1C and D). For the 24-h incubation period, half-maximal inhibitory concentration $\left(\mathrm{IC}_{50}\right.$ ) values were found to be: $5 \mathrm{nM}$ bortezomib and $300 \mathrm{nM}$ TSA in PC3 cells and 10 $\mathrm{nM}$ bortezomib and $300 \mathrm{nM}$ TSA in LNCaP cells.

\section{Effect of bortezomib and TSA on the expression of IkB $\alpha$ and caspase-3 genes}

We investigated the mRNA levels of IkB $\alpha$ and caspase- 3 genes after treatment with bortezomib and TSA for the indicated periods and doses and measured the alterations in gene expression in the $\mathrm{LNCaP}$ and $\mathrm{PC} 3$ cell lines.

After treating LNCaP cells with $400 \mathrm{nM}$ for $24 \mathrm{~h}$, the mRNA level of the IkB $\alpha$ gene was increased by approximately 1.5 -fold compared to the control, but the increase was not statistically significant. After $48 \mathrm{~h}$, the expression was 3.5-fold higher than after the 24-h 
period. After treatment for 24 and $48 \mathrm{~h}$ with $400 \mathrm{~nm}$ TSA, the mRNA level of the caspase-3 gene increased by 4.7- and 3.9-fold compared to control cells, respectively. These increases were statistically significant $(\mathrm{P}<0.05)$ (Figure 2A). After 24-h treatment with $400 \mathrm{~nm}$ TSA, the mRNA level of the IkB $\alpha$ gene in PC3 cells was 1.8-fold higher than in control cells and 2.5 -fold higher after $48 \mathrm{~h}$. After treatment for 24 and $48 \mathrm{~h}$ with $400 \mathrm{nM}$ TSA, the mRNA level of caspase-3 was 2.1- and 2.9-fold higher, respectively. These increases were statistically significant $(\mathrm{P}<0.05)$ (Figure 2A).
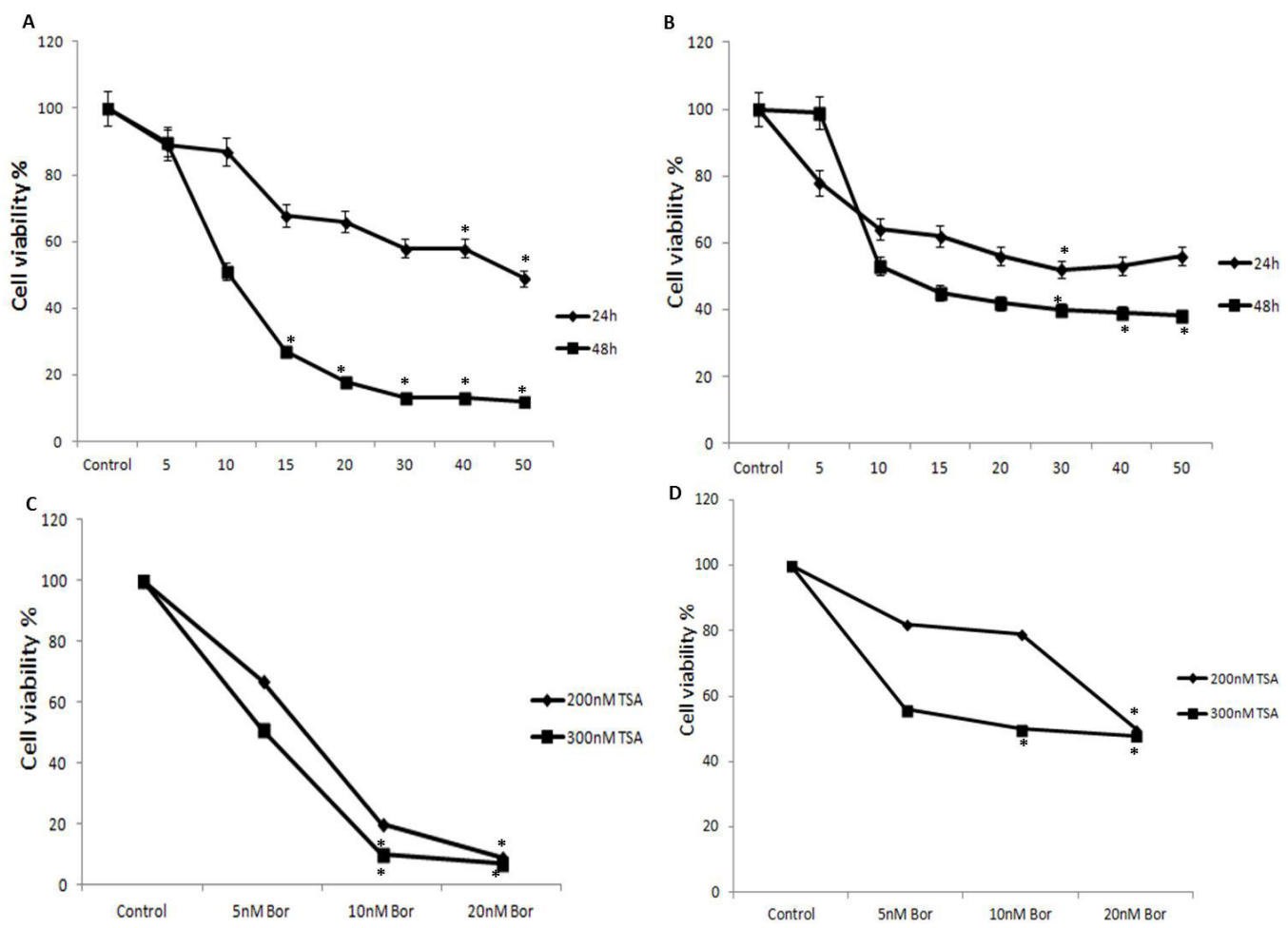

Figure 1. Trichostatin A (TSA) and bortezomib (Bor) effectively inhibit growth of prostate cancer cells. Decrease in cell viability of PC3 (A) and LNCaP (B) cells caused by bortezomib alone ( 24 and $48 \mathrm{~h}$ ), and combination with TSA $24 \mathrm{~h}$ (C. PC3, D. LNCaP). Effects of these drugs on cell viability were determined using the WST-1 assay. The results are reported as means \pm standard deviation of at least 3 independent experiments. Differences were considered to be significant in all experiments when $\mathrm{P}<0.05$.

After treating LNCaP cells with $30 \mathrm{nM}$ bortezomib for $24 \mathrm{~h}$, no significant changes were observed in the mRNA level of the $\mathrm{IkB} \alpha$ gene. However, after treatment with $10 \mathrm{nM}$ bortezomib for $48 \mathrm{~h}, \mathrm{IkB} \alpha$ mRNA was decreased by 2.3 -fold compared to the control $(\mathrm{P}<$ 0.01 ) (Figure $2 \mathrm{~B}$ ). While the caspase-3 mRNA level was significantly increased after treatment with $30 \mathrm{nM}$ bortezomib for $24 \mathrm{~h}(\mathrm{P}<0.05)$, treatment with $10 \mathrm{nM}$ bortezomib for $48 \mathrm{~h}$ only minimally increased caspase- 3 mRNA compared to the control (Figure 2B). This increase was lower than in the 24-h period and was not statistically significant. After treating PC3 
$\mathbf{2 A}$

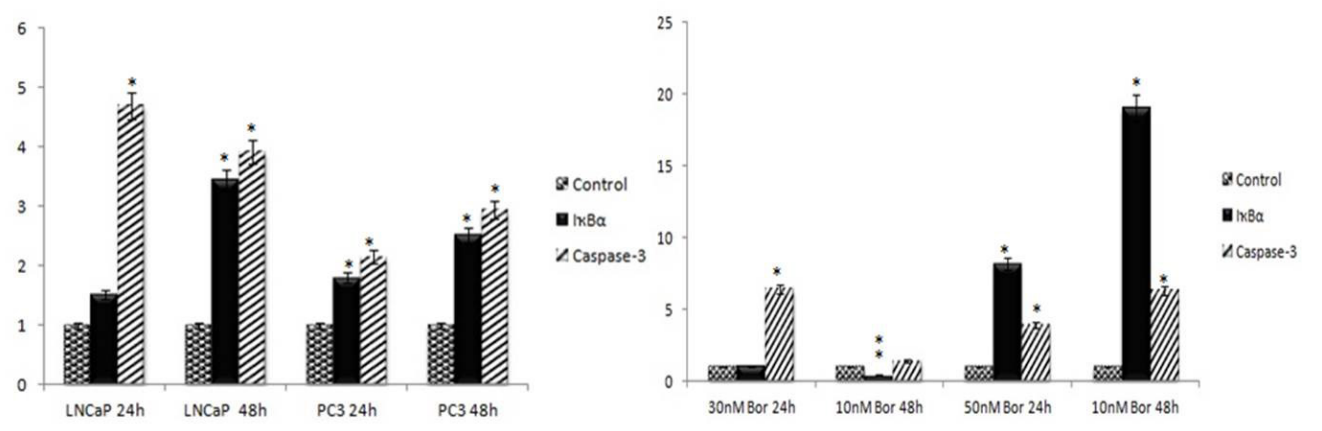

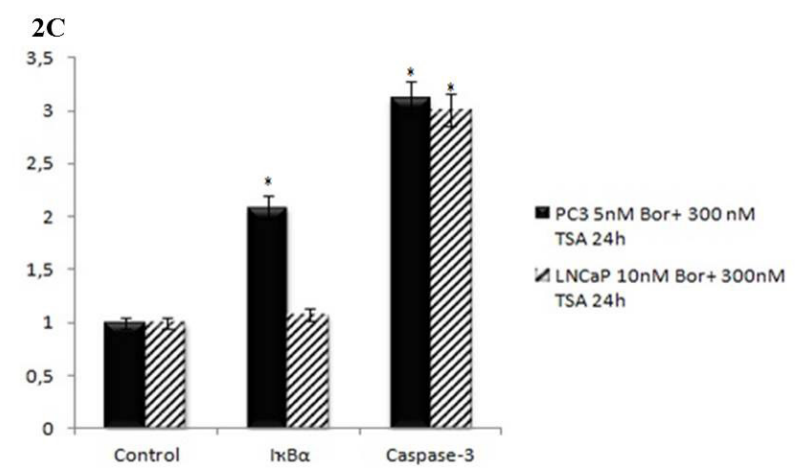

Figure 2. Effects of bortezomib (Bor) and trichostatin A (TSA) on mRNA expression levels of the IkB $\alpha$ and caspase-3 genes. Alterations of the relative mRNA expression levels of $\mathrm{IkB} \alpha$ and caspase- 3 genes in $\mathrm{LNCaP}$ and PC3 cell lines after treatment with bortezomib and TSA for times and doses indicated. The cells were treated with $400 \mathrm{nM}$ TSA alone (24 and $48 \mathrm{~h}$ ) (A), specified concentrations of bortezomib alone (24 and $48 \mathrm{~h})(\mathbf{B})$, and bortezomib plus TSA combination $(24 \mathrm{~h})(\mathbf{C})$. mRNA expression levels of these genes were normalized to glyceraldehyde 3 -phosphate dehydrogenase $(* \mathrm{P}<0.05 ; * * \mathrm{P}<0.01)$.

cells with $50 \mathrm{nM}$ bortezomib for $24 \mathrm{~h}, \mathrm{IkB} \alpha \mathrm{mRNA}$ increased by 8.2 -fold. After the treatment with $10 \mathrm{nM}$ bortezomib for $48 \mathrm{~h}, \mathrm{IkB} \alpha \mathrm{mRNA}$ increased by 19 -fold compared to the control. These increases were statistically significant $(\mathrm{P}<0.05)$ (Figure $2 \mathrm{~B})$. After treatment with 50 $\mathrm{nM}$ bortezomib for $24 \mathrm{~h}$, caspase- 3 mRNA was increased by 3.9 -fold compared to the control, while after treatment with $10 \mathrm{nM}$ bortezomib for $48 \mathrm{~h}$, caspase- 3 mRNA was increased by 6.3fold. These increases were statistically significant $(\mathrm{P}<0.05)$.

We also examined the effects of combination treatment with these drugs. After treating PC 3 cells with $5 \mathrm{nM}$ bortezomib and $300 \mathrm{nM}$ TSA for $24 \mathrm{~h}$, the levels of IkB $\alpha$ and caspase-3 mRNA increased by 2 - and 3 -fold, respectively $(\mathrm{P}<0.05)$ (Figure $2 \mathrm{C})$. After treating LNCaP cells with $10 \mathrm{nM}$ bortezomib and $300 \mathrm{nM}$ TSA for $24 \mathrm{~h}, \mathrm{IkB} \alpha$ and caspase- $3 \mathrm{mRNA}$ levels were not increased and increased by 3 -fold $(\mathrm{P}<0.05)$, respectively (Figure $2 \mathrm{C}$ ).

We also examined caspase- 3 activation at the protein level in both cell lines after treatment with bortezomib and TSA (Figure 3). After treatment with bortezomib alone, caspase-3 activation was observed in both PC3 (Figure 3A) and LNCaP (Figure 3B) cells. Induction of synergistic caspase- 3 activation by bortezomib and TSA were observed in both cell lines 
(Figure 3C). After treatment with $5 \mathrm{nM}$ bortezomib plus $300 \mathrm{nM}$ TSA in PC3 cells and $10 \mathrm{nM}$ bortezomib plus $300 \mathrm{nM}$ TSA in LNCaP cells, caspase-3 activation was observed. We also found that phosphorylation of the $\mathrm{IkB} \alpha$ gene after bortezomib treatment reached a maximum at $4 \mathrm{~h}$ in PC3 cells (Figure 3D), but phosphorylation was not observed in LNCaP cells.

A

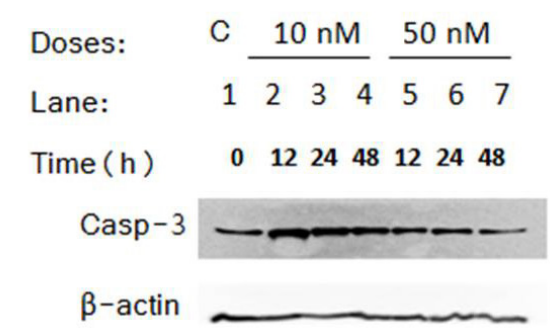

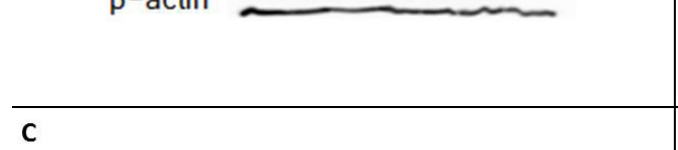

C

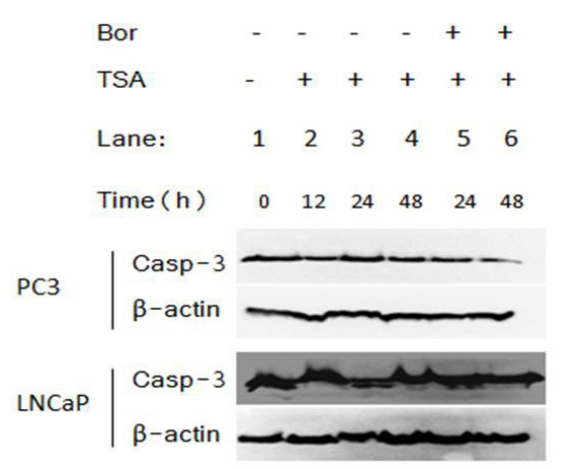

B Doses: $\quad$ C $10 \mathrm{nM} 30 \mathrm{nM}$ Lane: $\quad \begin{array}{lllllll}1 & 2 & 3 & 4 & 5 & 6 & 7\end{array}$ Time (h) $\quad 0 \quad 122448122448$

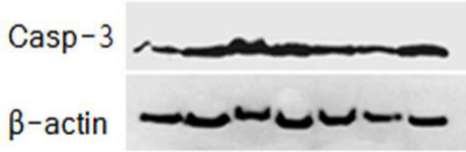

D

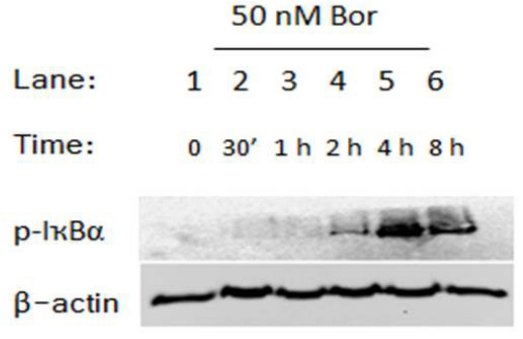

Figure 3. Analysis of effects of bortezomib and trichostatin A (TSA) treatment on p-IkB $\alpha$ and caspase-3 protein expression levels by Western blot. After treatment with the specified concentrations of bortezomib alone, caspase-3 activation occurred in both PC3 (A) and LNCaP (B) cells. Synergistic induction of caspase-3 activation by bortezomib and TSA was observed in both cell lines $(\mathbf{C})$. Caspase-3 activation occurred after treatment with $5 \mathrm{nM}$ bortezomib plus $300 \mathrm{nM}$ TSA in PC3 cells and $10 \mathrm{nM}$ bortezomib plus $300 \mathrm{nM}$ TSA in LNCaP cells. Phosphorylation of the IkB $\alpha$ gene after $50 \mathrm{nM}$ bortezomib treatment reached a maximum at $4 \mathrm{~h}$ in PC3 cells (D), but phosphorylation was not observed in LNCaP cells. (Bor = bortezomib, $\mathrm{C}=$ control).

\section{DISCUSSION}

In this study, we examined the cytotoxic and apoptotic effects of bortezomib and TSA alone or in combination on the prostate cancer cell lines LNCaP and PC3. In a study of the LNCaP and PC3 cell lines by Williams et al. (2003), an $\mathrm{IC}_{50}$ value of bortezomib reached approximately $10 \mathrm{nM}$ within $48 \mathrm{~h}$. We found a similar result, as the $\mathrm{IC}_{50}$ value at $48 \mathrm{~h}$ was $10 \mathrm{nM}$ for both cell lines. Sato et al. (2012) estimated the bortezomib $\mathrm{IC}_{50}$ value for the $\mathrm{LNCaP}$ and PC 3 cell lines to be 32 and $23 \mathrm{nM}$, respectively, which did not agree with our results (Williams et al., 2003; Sato et al., 2012). This can be attributed to factors such as laboratory conditions, 
cell density, the number of passages of cell cultures, or the substance in which the drug was dissolved. In another study by Ikezoe et al. (2004) on LNCaP cells, bortezomib inhibited cell growth and directed cells towards apoptosis. Because LNCaP cells are androgen-dependent, they were accompanied by high levels of prostate-specific antigen. Bortezomib treatment reduced the PSA level and increased the expression levels of the p53 and p21 genes (Ikezoe et al., 2004). We determined $\mathrm{IC}_{50}$ values after 24-h treatment with $30 \mathrm{nM}$ in LNCaP cells and $50 \mathrm{nM}$ in PC3 cells. Dose differences may have resulted from the different genetic profiles of these cells, particularly the p53 status. While LNCaP cells contain wild-type p53, this gene is mutated in PC3 cells (Papandreou and Logothetis, 2004). This may explain why PC3 cells required a larger dose of bortezomib.

Similarly to our results, Fronsdal and Saatcioglu (2005) observed varying effects of TSA on prostate cancer cell lines and found that compared to PC3 cells, LNCaP cells were more sensitive to TSA. Both studies showed that the HDAC inhibitors inhibited cell proliferation and induced apoptosis in various prostate cancers, as well as that TSA-induced cell death was higher in LNCaP cells than in PC3 cells (Fronsdal and Saatcioglu, 2005). LNCaP cells may be more sensitive to TSA compared to PC3 cells because of their p53 statuses. We analyzed the effects of bortezomib and TSA in different dose combinations on the viability of these cells. After treatment for $24 \mathrm{~h}$, the following $\mathrm{IC}_{50}$ values were found: $5 \mathrm{nM}$ bortezomib and $300 \mathrm{nM}$ TSA in PC3 cells; $10 \mathrm{nM}$ bortezomib and $300 \mathrm{nM}$ TSA in LNCaP cells. These values indicate that the drugs synergistically reduced cell proliferation. Thus, less exposure to a low-dose drug combination resulted in an anti-proliferative effect.

Constitutive activation of the NFkB transcription factor is closely associated with the development of more aggressive prostate cancer. Therefore, it is very important to prevent $\mathrm{IkB} \alpha$ degradation by bortezomib so that the target genes of NFkB are not activated. In studies targeting NFkB inhibition with dominant negative IkB $\alpha$ constructs, it was found that the invasion, metastasis, and angiogenesis of prostate cancer cells were suppressed (Papandreou and Logothetis, 2004). Furthermore, NFkB-dependent transcriptional activity in the PC3 cell line has been shown to be 10 times higher than in LNCaP and other non-invasive cells. This constitutive activity of NFkB is important for the progression of prostate cancer to the androgen-independent phase. While PC3 cells are androgen-independent, LNCaP cells are androgen-dependent. Although constitutive NFkB activity alone is not sufficient for androgen independence and other cellular factors must be involved to mediate androgen independence in prostate cancer cells, it appears that NFkB inhibition through proteasome inhibition or other methods is a potential cellular target for cancer treatment (Papandreou and Logothetis, 2004).

$\mathrm{Vu}$ et al. (2008) found that another proteasome inhibitor, MG-132, induced apoptosis in PC3 cells by inhibiting the NFkB pathway and accumulation of cytoplasmic $\mathrm{IkB} \alpha$ ( $\mathrm{Vu}$ et al., 2008). Patrikidou et al. (2011) compared the total amount of $\mathrm{IkB} \alpha$ in untreated PC3 and $\mathrm{LNCaP}$ cells and found that $\mathrm{IkB} \alpha$ levels were greater in LNCaP cells, indicating high NFkB activity in PC3 cells. After exposure to bortezomib, PC3 cells showed time-dependent accumulation of $\mathrm{IkB} \alpha$. This indicates that the NFkB pathway was inhibited by bortezomib. In this study, we also observed time-dependent IkB $\alpha$ accumulation in PC3 cells after exposure to bortezomib. However, we did not observe IkB $\alpha$ accumulation in LNCaP cells. This also explains why the NFkB pathway functions differently in PC3 and LNCaP cells. In addition, the increase in caspase-3 expression levels paralleled the increase in $\mathrm{IkB} \alpha$ accumulation, which was significantly observed in both cell lines. This indicates through inhibition by bortezomib, 
the NFkB may cause apoptosis. However, other cellular mechanisms may also play a role in apoptosis when the proteasome is inhibited; hence, other factors may be involved in this process. We also determined IkB $\alpha$ phosphorylation at the protein level in PC3 cells. Phosphorylation is the basis for proteasome-mediated degradation of $\mathrm{IkB} \alpha$. However, we did not observe such phosphorylation in LNCaP cells. This may have been because of the high IkB $\alpha$ activity in PC 3 cells. We also observed a significant increase in caspase- 3 activation in both cell lines after exposure to a combination of bortezomib and TSA. Caspase enzymes belong to a large family of protease enzymes, and caspase- 3 is an effector caspase. Extrinsic and intrinsic pathways of apoptosis merge at the level of caspase-3 activation (Hyman and Yuan, 2012). Thus, increased caspase- 3 activation indicates that treatment with these drugs lead to apoptosis in both cell lines.

In conclusion, we demonstrated that combination treatment with the proteasome inhibitor bortezomib and HDAC inhibitor TSA potently inactivated NFkB and induced CaP cell death, resulting in significantly increased protein levels of caspase-3.

\section{ACKNOWLEDGMENTS}

Research supported by the Gazi University Research Fund and assigned the project code number \#01/2012-47.

\section{REFERENCES}

Bai J, Demirjian A, Sui J, Marasco W, et al. (2006). Histone deacetylase inhibitor trichostatin A and proteasome inhibitor PS-341 synergistically induce apoptosis in pancreatic cancer cells. Biochem. Biophys. Res. Commun. 348: 1245-1253.

Chang J, Varghese DS, Gillam MC, Peyton M, et al. (2012). Differential response of cancer cells to HDAC inhibitors trichostatin A and depsipeptide. Br. J. Cancer 106: 116-125.

Chitra S, Nalini G and Rajasekhar G (2012). The ubiquitin proteasome system and efficacy of proteasome inhibitors in diseases. Int. J. Rheum. Dis. 15: 249-260.

Crawford LJ, Walker B and Irvine AE (2011). Proteasome inhibitors in cancer therapy. J. Cell Commun. Signal. 5: 101-110.

Ellis L and Pili R (2010). Histone deacetylase inhibitors: advancing therapeutic strategies in hematological and solid malignancies. Pharmaceuticals 3: 2411-2469.

Fang Y, Hu Y, Wu P, Wang B, et al. (2011). Synergistic efficacy in human ovarian cancer cells by histone deacetylase inhibitor TSA and proteasome inhibitor PS-341. Cancer Invest. 29: 247-252.

Frankland-Searby S and Bhaumik SR (2012). The 26S proteasome complex: an attractive target for cancer therapy. Biochim. Biophys. Acta 1825: 64-76.

Fribley A, Zeng Q and Wang CY (2004). Proteasome inhibitor PS-341 induces apoptosis through induction of endoplasmic reticulum stress-reactive oxygen species in head and neck squamous cell carcinoma cells. Mol. Cell Biol. 24: 9695-9704.

Fronsdal K and Saatcioglu F (2005). Histone deacetylase inhibitors differentially mediate apoptosis in prostate cancer cells. Prostate 62: 299-306.

Hyman BT and Yuan J (2012). Apoptotic and non-apoptotic roles of caspases in neuronal physiology and pathophysiology. Nat. Rev. Neurosci. 13: 395-406.

Ikezoe T, Yang Y, Saito T, Koeffler HP, et al. (2004). Proteasome inhibitor PS-341 down-regulates prostate-specific antigen (PSA) and induces growth arrest and apoptosis of androgen-dependent human prostate cancer LNCaP cells. Cancer Sci. 95: 271-275.

Kim HJ and Bae SC (2011). Histone deacetylase inhibitors: molecular mechanisms of action and clinical trials as anticancer drugs. Am. J. Transl. Res. 3: 166-179.

Kim J, Guan J, Chang I, Chen X, et al. (2010). PS-341 and histone deacetylase inhibitor synergistically induce apoptosis in head and neck squamous cell carcinoma cells. Mol. Cancer Ther. 9: 1977-1984.

Mukhopadhyay NK, Weisberg E, Gilchrist D, Bueno R, et al. (2006). Effectiveness of trichostatin A as a potential candidate for anticancer therapy in non-small-cell lung cancer. Ann. Thorac. Surg. 81: 1034-1042. 
Papandreou CN and Logothetis CJ (2004). Bortezomib as a potential treatment for prostate cancer. Cancer Res. 64: 50365043.

Patrikidou A, Vlachostergios PJ, Voutsadakis IA, Hatzidaki E, et al. (2011). Inverse baseline expression pattern of the $\mathrm{NEP} /$ neuropeptides and $\mathrm{NF \kappa B} /$ proteasome pathways in androgen-dependent and androgen-independent prostate cancer cells. Cancer Cell Int. 11: 13.

Pfaffl MW, Horgan GW and Dempfle L (2002). Relative expression software tool (REST) for group-wise comparison and statistical analysis of relative expression results in real-time PCR. Nucleic Acids Res. 30: e36.

Ramsay AK and Leung HY (2009). Signalling pathways in prostate carcinogenesis: potentials for molecular-targeted therapy. Clin. Sci. 117: 209-228.

Sato A, Asano T, Ito K and Asano T (2012). Vorinostat and bortezomib synergistically cause ubiquitinated protein accumulation in prostate cancer cells. J. Urol. 188: 2410-2418.

Shahshahan MA, Beckley MN and Jazirehi AR (2011). Potential usage of proteasome inhibitor bortezomib (Velcade, PS341 ) in the treatment of metastatic melanoma: basic and clinical aspects. Am. J. Cancer Res. 1: 913-924.

Taghiyev AF, Guseva NV, Glover RA, Rokhlin OW, et al. (2006). TSA-induced cell death in prostate cancer cell lines is caspase-2 dependent and involves the PIDDosome. Cancer Biol. Ther. 5: 1199-1205.

Tavakoli-Yaraki M, Karami-Tehrani F, Salimi V and Sirati-Sabet M (2013). Induction of apoptosis by trichostatin A in human breast cancer cell lines: involvement of 15-Lox-1. Tumour. Biol. 34: 241-249.

Verma M, Patel P and Verma M (2011). Biomarkers in prostate cancer epidemiology. Cancers 3: 3773-3798.

Voutsadakis IA and Papandreou CN (2012). The ubiquitin-proteasome system in prostate cancer and its transition to castration resistance. Urol. Oncol. 30: 752-761.

Vu HY, Juvekar A, Ghosh C, Ramaswami S, et al. (2008). Proteasome inhibitors induce apoptosis of prostate cancer cells by inducing nuclear translocation of IkB $\alpha$. Arch. Biochem. Biophys. 475: 156-163.

Williams S, Pettaway C, Song R, Papandreou C, et al. (2003). Differential effects of the proteasome inhibitor bortezomib on apoptosis and angiogenesis in human prostate tumor xenografts. Mol. Cancer Ther. 2: 835-843.

Yeramian A, Sorolla A, Velasco A, Santacana M, et al. (2012). Inhibition of activated receptor tyrosine kinases by sunitinib induces growth arrest and sensitizes melanoma cells to bortezomib by blocking Akt pathway. Int. J. Cancer 130: 967-978.

Zhu S, Li Y, Zhao L, Hou P, et al. (2012). TSA-induced JMJD2B downregulation is associated with cyclin B1-dependent survivin degradation and apoptosis in LNCap cells. J. Cell Biochem. 113: 2375-2382. 